\title{
GASTROENTERITE EOSINOFÍLICA EM UM IDOSO: RELATO DE CASO
}

\author{
Maviel Sousa PEREIRA ${ }^{1}$, Roger Willian PIRES ${ }^{2 *}$, Sarah Madeira JACINTO ${ }^{1}$, Franciane Aparecida \\ Marques SANTOS ${ }^{1}$, Eveline de Almeida $L_{U Z}{ }^{1}$ \& Rafael Marcondes Ramos BRUM ${ }^{1}$
}

\begin{abstract}
1 Hospital São José do Avaí, Itaperuna, Rio de Janeiro, Brasil.
2 Universidade Iguaçu (UNIG), Campus V, Itaperuna, Rio de Janeiro, Brasil.

*Autor para correspondência: mavibob@hotmail.com
\end{abstract}

DOI: http://dx.doi.org/10.18571/acbm.164

\section{RESUMO}

A Gastroenterite Eosinofílica (GE) é uma doença rara, crônica, de etiologia ainda desconhecida e com uma apresentação heterogênea, caracterizada por infiltração maciça de eosinófilos em, pelo menos, um dos segmentos do trato gastrointestinal. Seu quadro clinico é variável conforme o local e profundidade da infiltração, apresentando desde sintomas gastrointestinais comuns até doença oclusiva intestinal - o que torna a clínica inespecífica, exigindo alta suspeição, comprovação histológica e exclusão de várias patologias associadas a eosinofilia periférica para o fechamento do diagnóstico, sendo uma patologia possivelmente subdiagnósticada. Apresentamos o caso de um adulto com diarréia líquida e perda ponderal significativa, sem melhoras ao uso de medicamentos. Tratava-se de uma Gastroenterite Eosinofílica, patologia de exclusão, que respondeu ao uso de corticóide, estando assintomático até a descrição deste relato.

Palavras chave: Diagnóstico; Eosinofilia; Gastroenterite; Trato Gastrointestinal.

\section{ABSTRACT}

Eosinophilic Gastroenteritis in an elderly man: Case Report. Eosinophilic Gastroenteritis (GE) is a rare, chronic, disease of unknown etiology with a heterogeneous presentation, characterized by massive infiltration of eosinophils in at least one segment of the gastrointestinal tract. Its clinical condition varies according to the site and depth of the infiltration, ranging from common gastrointestinal symptoms to intestinal occlusive disease - which makes the clinic unspecific, requiring high suspicion, histological confirmation and exclusion of several pathologies associated with peripheral eosinophilia for the diagnosis closure, being a pathology possibly underdiagnosed. We present the case of an adult with liquid diarrhea and significant weight loss, with no improvement in medication use. It was an Eosinophilic Gastroenteritis, a pathology of exclusion, which responded to the use of corticosteroids, being asymptomatic up to the description of this report.

Keywords: Diagnosis; Eosinophilia; Gastroenteritis; Gastrointestinal Tract.

\section{Introdução}

A Gastroenterite Eosinofílica (GE) é uma doença inflamatória rara, crônica e de etiologia ainda desconhecida com uma apresentação heterogênea, podendo acometer tanto crianças como adultos, sendo mais frequente na terceira e quinta década de vida (JIMÉNEZ et al., 2011). A patologia foi descrita inicialmente por Kaijser em 1937, possuindo poucos relatos na literatura desde então. Caracteriza-se por presença de infiltrado de eosinófilos em um ou mais segmentos do trato gastrointestinal (TGI), acometendo uma ou mais camadas, variando assim o seu quadro clinico de acordo com a camada acometida (SERNA HIGUERA et al., 2002; SOUZA et al., 2000). 
Mesmo que a doença receba em seu nome gastroenterite, ela pode afetar todo o TGI, do esôfago ao reto. A GE pode ser enquadrada no grupo de patologias conhecidas como desordens gastrointestinais eosinofílicas, esse grupo de doenças tem por característica a presença de infiltração rica em eosinófilos, na ausência de outras causas para eosinofilia dentro do TGI (LEAL e NARCISO-SCHIAVON, 2014).

A infiltração em camadas ou de locais distintos dentro do trato gastrointestinal torna as manifestações clinicas inespecíficas, variando desde dor abdominal, náuseas, vômitos e diarreia, perda de peso e obstrução intestinal exigindo que o diagnóstico seja realizado através de exclusão de várias patologias associadas a eosinofilia do TGI (FAJARDO e CASTILLO, 2013; JIMENEZ et al., 2011).

O diagnóstico de GE é realizado com uma alta suspeição clinica, demonstração histológica de infiltrado eosinofílico no TGI e afastamento de outras causas conhecidas para a eosinofilia periférica (SERNA HIGUERA et al., 2002), há de se observar que a distribuição irregular da doença, assim como a possível presença de formas sem infiltração da mucosa, podem gerar falsos negativos frequentes nas amostras de biópsia, acarretando possíveis subdiagnósticos, sendo recomendado múltiplas biopsias no esôfago, estômago e intestino, mesmo que a mucosa tenha um aspeto normal, para obtenção da confirmação diagnostica de gastroenterite eosinofílica (LIMA et al., 2012).

O tratamento da GE é realizado através do uso de corticosteroides e imunossupressores, tendo em vista os mecanismos imunoalérgicos associados a doença. $\mathrm{O}$ uso de dieta é recomendado visando evitar exacerbação da patologia devido irritação da mucosa ou processos alérgicos, sendo os corticoides a primeira escolha no tratamento medicamentoso, por possuírem boa resposta e tolerância, em casos mais raros e graves com obstrução intestinal pode ser necessário a utilização de procedimentos cirúrgicos para resolução do quadro (GARIBAY-VARGAS et al., 2014; FAJARDO e CASTILLO, 2013).

O prognóstico para os pacientes com gastroenterite eosinofílica é favorável mesmo que comumente haja exacerbação clinica, não há ocorrência de sequelas graves, que acarreta em diminuição da expectativa de vida (SERNA HIGUERA et al., 2002).

\section{Relato de caso}

JJB, 74 anos, masculino, aposentado, natural de São José de Ubá - RJ, procurou atendimento queixando-se de dor abdominal difusa e de forte intensidade (7 em uma escala de 1 a 10), associada a quadros de diarreia liquidas e com presença de muco, falta de apetite e perda ponderal de $12 \mathrm{~kg}$ em 7 meses. Em uso recorrente de Imosec para controle do quadro de diarréia. Hipertenso, quadro de Infarto Agudo do Miocárdio (IAM) há aproximadamente 10 anos, etilista e tabagista, paciente nega qualquer tipo de alergia.

$\mathrm{Na}$ admissão paciente encontrava-se em bom estado geral, emagrecido, hipocorado $+/+4$, acianótico, anictérico, hidratado, ausência de adenomegalias, abdome flácido e indolor a palpação, com ruídos hidroaéreos positivo, presença de cicatriz mediana, sem visceromegalias, membros inferiores com edema $+/+4$.

Os exames laboratoriais iniciais demonstraram um hemograma com presença de 9.600 Leucócitos com eosinofília (9\%). Solicitado exames complementares. Na endoscopia digestiva alta (EDA) foi observado gastrite enantematosa leve de antro e atrofia de mucosas de $1^{\circ}$ e $2^{\circ}$ porção duodenal que pode ser observada na figura 1, realizada biópsia que demonstrou ser uma duodenite eosinofílica focal com grupamentos de infiltração eosinofílicas, perfazendo mais de 20 eosinófilos por campo de aumento. 


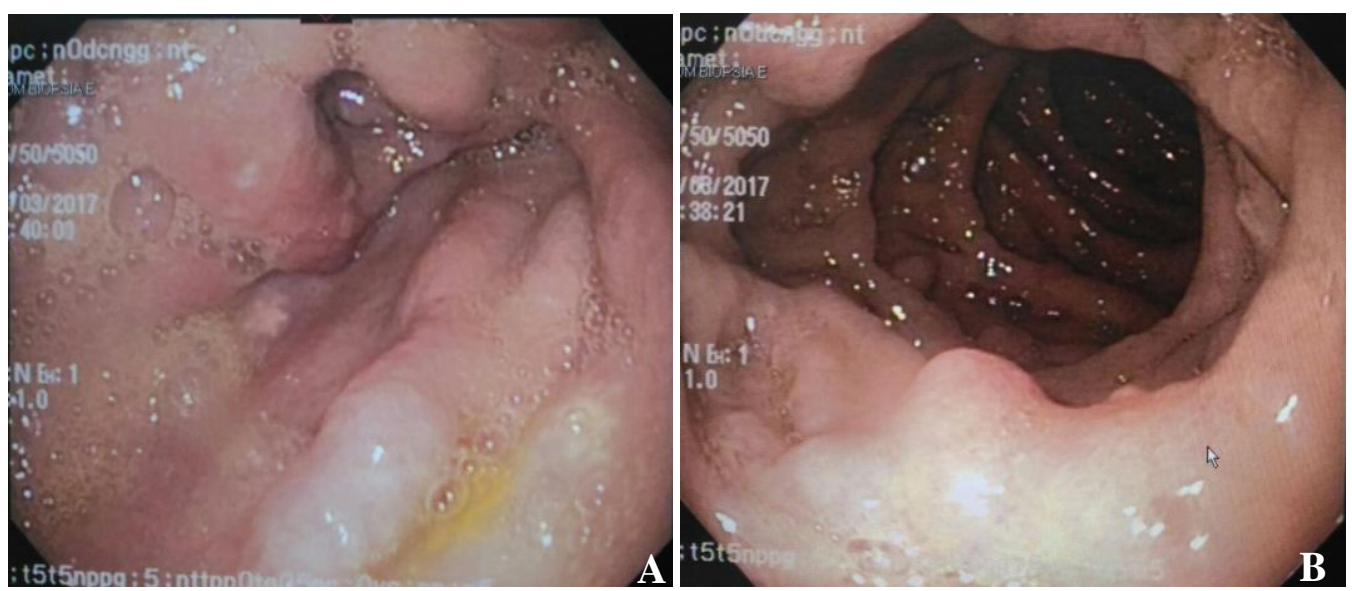

Figura 1: (A) Endoscopia digestiva alta do estomago demonstrando gastrite enantematosa leve de antro. (B) Endoscopia digestiva alta do duodeno demonstrando atrofia na $1^{\circ}$ e $2^{\circ}$ porção.

A colonoscopia não evidenciou achados significativos. $\mathrm{Na}$ enterorresonância foi constatado espessamento parietal do antro gástrico, primeira porção do duodeno e de alças jejunais, com achados sugestivos de natureza inflamatória. Parasitológico de fezes, sorologias virais, HIV, anticorpos para doença celíaca, calprotectina fecal, função tireoidiana e glicemia sem alterações.

Durante todo o processo de investigação que durou cerca de seis meses, foram afastadas diversas patologias causadoras de eosinofilia no trato gastrointestinal e diarreia crônica, principalmente parasitoses e doença inflamatória intestinal. Diante dos achados de exames de imagem, exclusão de outras causas e a resposta dramática a corticoterapia $(40 \mathrm{mg} / \mathrm{dia})$ fecha-se o diagnóstico de Gastroenterite Eosinofílica. Atualmente paciente encontra-se assintomático e em dose decrescente de corticoide ( $5 \mathrm{mg} / \mathrm{dia})$.

\section{Discussão}

A Gastroenterite Eosinofílica afeta qualquer faixa etária, mas tem uma maior incidente nos adultos entre a terceira e quinta década de vida, tendo predominância no sexo masculino, com uma incidência de 1 a 30 doentes/100.000 (CIANFERONI e SPERGEL, 2015), ainda que com etiologia desconhecida, em cerca de $70 \%$ dos pacientes há alguma história de alergia, sendo relatado na literatura a não associação com alergia para a ocorrência da patologia (TROIANI et al., 2010), Neste relato o paciente estava com idade superior ao pico de incidência, e negava alergias.

A Gastroenterite Eosinofílica pode ser dividida em três formas conforme sua apresentação histopatológica segundo a classificação de Klein, sendo a predominantemente mucosa $(57,5 \%$ dos casos), predominantemente muscular (30\% dos casos) ou predominantemente serosa $(12,5 \%$ dos casos) (MORETTI et al., 2006; LIMA et al., 2012), sua clínica comumente se apresenta como dor abdominal, diarreia, vômitos, emagrecimento, anemia, ascite e obstrução intestinal. Quando se dividem os sintomas conforme a camada acometida é observada acometimento do tecido mucoso: náuseas, vomito, diarreia, dor abdominal, ulceração, perda de proteínas, síndrome de má-absorção, emagrecimento e anemia, sendo a mais comumente diagnosticada. A camada muscular observase obstrução intestinal, náuseas, vômitos, dor e distensão abdominal. Enquanto o acometimento da camada serosa se traduz em presença de ascite com uma excelente resposta aos corticosteroides (SOUZA et al., 2000; FAJARDO e CASTILLO, 2013; TALLEY et al. 1990). No presente relato o paciente apresentou junto a uma eosinofilia um quadro de dor abdominal, diarreia e emagrecimento, acompanhando desta forma os quadros clínicos comuns da patologia com acometimento do tecido mucoso.

Seu diagnóstico é difícil e requer uma alta suspeição devido à variação da apresentação clinica, a presença de eosinofilia periférica está ausente em aproximadamente $20 \%$ dos pacientes, 
não sendo um critério de diagnostico, os critérios para fechamento do quadro demanda a identificação de sintomas gastrointestinais, presença de infiltração eosinofílica em uma ou mais área do TGI em um número superior a 20 eosinófilos por campo de grande ampliação, ausência de outras de envolvimento extra-intestinal e de parasitose intestinal (LEAL et al., 2000; MORETTI et al. 2006). A suspeição no caso relatado foi confirmada através do quadro de dor abdominal, diarreia e perda ponderal, assim como infiltração de eosinófilos no TGI confirmada por biopsia, e descartada outras causas de infiltração de eosinofilia e/ou parasitose.

Os corticoides são a primeira escolha no tratamento da GE as doses variam entre 20 e 40 mg, com redução progressiva até alcançar o controle dos sintomas (MORETTI et al., 2006), sendo administrado com excelente resposta ao nosso paciente, em redução da dose e com o quadro clínico controlado. O prognóstico em sua maioria das vezes é benigno. Recaídas são comuns frequentemente observadas quando a dosagem dos esteroides é diminuída ou seu uso suspenso (SERNA HIGUERA et al., 2002).

\section{Conclusão}

A Gastroenterite eosinofílica é uma patologia rara com diagnostico de exclusão, com o tratamento baseado fundamentalmente na corticoterapia com redução progressiva das dosagens, visando a diminuição dos sintomas. $\mathrm{O}$ uso de dietas restritivas para o equilíbrio nutricional é recomendado visto que uma acentuada parcela dos casos está envolvida com quadros de alergias. O prognóstico é considerado favorável, sem complicações severas, mas recidivas são comuns. Ainda há uma necessidade de se estabelecer diretrizes capazes de sistematizar o atendimento, diagnóstico precoce e intervenção adequada visando o atendimento eficaz, melhorando a qualidade de vida de pacientes acometidos pela patologia.

\section{Referências}

CIANFERONI, A. \& SPERGEL, J. M. Eosinophilic Esophagitis and Gastroenteritis. Curr. Allergy Asthma Rep. 15, 58. 2015.

FAJARDO, Luis Fernández; CASTILLO, Odenis Castro. Revisión actualizada sobre la Gastroenteritis Eosinofílica. Archivos del Hospital Universitario "General Calixto García", [S.1.], v. 1, n. 1, nov. 2013.

GARIBAY-VARGAS, Ondina Marlene et al. Gastroenteritis eosinofílica. Rev Alergia Mex. 2014; 61(3): 212-218.

JIMÉNEZ, Rodríguez B. et al. Eosinophilic gastroenteritis due to allergy to cow's milk. J Investig Allergol Clin Immunol. 2011; Vol. 21(2): 150-152.

LEAL, R.A.; NARCISO-SCHIAVON J.L. Gastroenterite eosinofílica. Revista da Sociedade Brasileira de Clínica Médica, v. 12, p. 259-262, 2014.

LEAL, Rodríguez $\mathrm{C}$ et al. Gastroenteritis eosinofílica. Medicine: Programa de Formación Médica Continuada Acreditado, Vol. 8, № 5, 2000, págs. 238-242.

LIMA J, REBELO M, CASTELLANO A, MOTA J, RUIVO C, DIAS P, et al. Gastroenterite eosinofílica, divertículo duodenal intraluminal como fator predisponente? GE J PortGastroenterol. 2012; 19(3): 146-50. 
MORETTI, Marcelo Pasquali et al. Gastroenterite eosinofílica: um relato de caso. ACM arq. catarin. med; 35(4): 104-107, out.-dez. 2006.

SERNA HIGUERA, C. de la et al. Gastroenteritis eosinofílica: espectro clínico de una misma entidad. An. Med. Interna (Madrid), v. 19, n. 7, p. 43-46, jul. 2002.

SOUZA, H. S. P. et al. Eosinophilic gastroenteritis. REVISTA BRASILEIRA DE MEDICINA, v. 57, n. 9, p. 1065-1070, 2000.

TALLEY NJ, Shorter RG, Phillips SF, Zinsmeister AR. Eosinophilic gastroenteritis: a clinicopathological study of patients with disease of the mucosa, muscle layer and subserosal tissues. Gut 1990; 31: 54-58.

TROIANI, C.; NASCIMENTO, M. U. do; MAIA, K. F.; CARRILHO, P. A. M. ; SESTI, F. S. . Gastroenterite eosinofílica: relato de caso. GED. Gastroenterologia e Endoscopia Digestiva, v. 29, p. 16-19, 2010. 